\title{
Ocular morbidity in infants of very low birth weight
}

\author{
C. G. KEITH AND W. H. KITCHEN
}

From the Royal Children's Hospital, Melbourne, and the Royal Women's Hospital, Melbourne

SUMMARY In the years 1977-8, 258 infants weighing less than $1500 \mathrm{~g}$ were born at, or transferred to, the Royal Women's Hospital, Melbourne; 177 (68.5\%) survived, and 111 of these attended for an ophthalmic examination. Significant ocular lesions were found in $37(33 \%): 21(19 \%)$ children had squint, $19(17 \%)$ had a significant refractive error, $11(10 \%)$ had cicatricial retrolental fibroplasia (RLF), and $3(2 \cdot 7 \%)$ had very poor vision due to optic atrophy associated with cerebral palsy. No children were blind owing to RLF, indicating that the recent increase in survival rate of infants of very low birth weight has not been accompanied by an increase in the prevalence of severe RLF. In those children with neither cerebral palsy nor RLF the prevalence of squint was $11 \%$ and of refractive errors $13 \%$. Myopia was found mainly in children who had shown RLF changes in the neonatal period. It is recommended that infants of very low birth weight continue to be screened in the premature nursery for RLF, and also at the age of 2 , for the detection of refractive errors and squint.

The introduction of intensive care units into neonatal nurseries has caused a significant increase in the survival rate of infants of very low birthweight (VLBW) (500-1500 g), and there has been considerable concern that it might also have caused an increase in the prevalence of children with severe neurosensory disorders. In order to assess this a collaborative study has been carried out on the neurosensory status of surviving VLBW infants born in the years 1977-8, when they reached the age of 2 years. The general data have been published elsewhere, ${ }^{1}$ and in this paper the ocular findings from one of the 2 participating hospitals are reported.

\section{Material and methods}

In the years 1977-8 258 VLBW infants were born in, or transfered in the neonatal period, to the Royal Women's Hospital, Melbourne. Seventy-four children succumbed in the hospital, and 7 children later died at home, giving a total mortality of 81 $(31.5 \%)$. Of the 177 long-term survivors $2(1 \cdot 1 \%)$ were untraced, reliable reports on 3 children $(1.7 \%)$ suggested no ocular abnormality, and $172(97.2 \%)$ were reviewed by the developmental paediatrician at 2 years of age. Although appointments were offered

Correspondence to Mr C. G. Keith, FRACS, Department of Ophthalmology, Royal Children's Hospital, Flemington Road, Parkville 3052, Melbourne, Victoria, Australia. to all families, only $111(63 \%)$ attended for ophthalmic examination by one of the authors (C.G.K.). Eighty of these 111 had been screened in the premature nursery for retrolental fibroplasia by methods previously described. ${ }^{2}$ Twenty-one children weighed less than $1000 \mathrm{~g}$ at birth, and 90 weighed between 1000 and $1500 \mathrm{~g}$.

The ocular examination consisted of visual acuity assessment with the Catford drum, inspection and cover test for the detection of squint, refraction after instillation of cyclopentolate $1 \%$ drops, and scrutiny of the fundus for cicatricial retrolental fibroplasia (RLF) and arteriolar tortuosity. All data were prepared for computer analysis.

\section{Results}

Among the 111 children reviewed one or more significant ocular defects were found in $37(33 \%)$ (Table 1). In $21(19 \%)$ there was a squint, $19(17 \%)$ had a significant refractive error, and $11(10 \%)$ had cicatricial RLF. There were 15 children with cerebral

Table 1 Significant ocular defects found in 37 children out of 111 reviewed

$\begin{array}{lc}\text { Squint } & 21(19 \%) \\ \text { RLF } & 11(10 \%) \\ \text { Optic atrophy } & 3(2 \cdot 7 \%) \\ \text { Refractive error } & 19(17 \%)\end{array}$


Table 2 Grades of RLF found in 11 children (19 eyes). Three eyes were clinically normal

\begin{tabular}{cc}
\hline Grade & Eyes \\
\hline I & 9 \\
II & 7 \\
III & 2 \\
IV & 1 \\
Total & 19 \\
\hline
\end{tabular}

Table 3 Refractive errors in dioptres found in the 6 cases of $R L F$ with myopia

\begin{tabular}{lllllll}
\hline $\mathrm{R}$ & -2 & -9 & -7 & -7 & -0 & -4 \\
$\mathrm{~L}$ & -4 & -9 & -0 & -9 & -7 & -9 \\
\hline
\end{tabular}

Table 4 The refractive status of the 21 children with squint (20 convergent, 1 vertical). The number with cerebral palsy are indicated separately

\begin{tabular}{lrc}
\hline Refractive status & \multicolumn{2}{c}{$\begin{array}{l}\text { No. of children } \\
\text { (cerebral palsy) }\end{array}$} \\
\hline No refractive error & 13 & (5) \\
Hypermetropia $\geq 3 \mathrm{D}$ & 2 & \\
Myopia/astigmatism $\geq 2 \mathrm{D}$ & 3 & $(1)$ \\
Hypermetropic/astigmatism $\geq 2 \mathrm{D}$ & 3 & $(1)$ \\
Total & 21 & \\
\hline
\end{tabular}

Table 5 Refractive errors found in 19 children

\begin{tabular}{ll}
\hline Refractive errors & No. of children \\
\hline Hypermetropia $\geq 3 \mathrm{D}$ & 3 \\
Myopia $\geq 2 \mathrm{D}$ & 6 \\
Myopic/astigmatism $\geq 2 \mathrm{D}$ & 2 \\
Hypermetropic/astigmatism $\geq 2 \mathrm{D}$ & 8 \\
Total & 19 \\
\hline
\end{tabular}

palsy, 7 had squint, and 3 had very poor vision due to optic atrophy. In a prior report ${ }^{1}$ only 2 of these children had been detected.

Cicatricial RLF was found in 19 eyes of 11 children (Table 2). Grade I was found in 9, grade II in 7, grade III in 2, and grade IV in 1 . These changes were sometimes asymmetrical, as in case 5430 , who had a retinal fold in the right eye (grade IV), while the left was normal. Eight $(7 \%)$ of the children had grade II-IV RLF in one or both eyes. There was no obvious difference in the severity of RLF occurring in those weighing less than $1000 \mathrm{~g}$ at birth, and those weighing between 1000 and $1500 \mathrm{~g}$. However, RLF was significantly more common in the former group, being found in 6 out of $21(19 \%)$, but in 5 out of $90(5.5 \%)$ in the latter group $(\mathrm{p}>0 \cdot 01)$.

In 8 of the 11 children, developing RLF had been detected in the nursery, 2 had not been screened, and in the remaining child the retinal periphery was not seen clearly when examined in the special care nursery. Six of the 11 children had myopia, and the refractive errors were mainly high (Table 3); one child had hypermetropic astigmatism, and 4 were emmetropic. Two children had squint, one convergent, one vertical. No children were blind because of RLF, and only one eye had severely reduced vision, due to a retinal fold (grade IV).

Of the 21 children with squint, in 20 it was convergent, and in one it was vertical. The refractive status of these children is shown in Table 4, in which it can be seen that there was no significant refractive error in 13 , hypermetropia in 2 , myopia with or without astigmatism in 3 , and simple hypermetropic astigmatism in 3 . Seven of the children with squint had cerebral palsy and RLF was present in 2 .

The refractive errors found in 19 children showed a predominance of myopia and hypermetropic astigmatism (Table 5), but myopia was particularly associated with cicatricial RLF, being found in 6 out of the 8 cases. The prevalence of refractive errors in children without RLF was $13 \%$.

\section{Discussion}

The ocular morbidity was high in this group of VLBW infants, and this may be due to the considerable bias for those children with known, or easily recognisable defects, to have attended for the ophthalmological examination. Thus the figures may be artificially high, but on scrutinising the available data on the 66 children who did not have an eye examination we found that 6 had developing RLF when examined in the premature nursery, and 6 had cerebral palsy; a further 4 children had squint diagnosed by other ophthalmologists. So this group of children would not have been free from ocular problems. In view of this it was felt that the group examined was a representative sample of VLBW infants, and that the given figures are a valid estimate of the prevalence of ocular defects.

The incidence and severity of RLF has fluctuated greatly over the past 40 years, but it is relevant to compare the present state with that pertaining before intensive care procedures were in common use, but when oxygen levels were monitored by arterial sampling, and some transcutaneous monitoring was performed. Gunn et al. ${ }^{3}$ reported on babies born 1975-6, none of whom had assisted respiration, and found a $60.5 \%$ survival rate of infants weighing $501-1500 \mathrm{~g}, 80$ of the 95 survivors had an ophthalmological examination after discharge from hospital, and $27(33.8 \%)$ were found to have RLF. Eight (10\%) of these were in grades II-V, and $2(2.5 \%)$ were completely blind.

In the series reported in this present paper cicatricial RLF was found in $11(10 \%)$ of VLBW infants, $8(7 \%)$ of whom were in grade II-IV, and 
significant ocular problems occurred in 7 , but none was blind. This finding does not seem to be fortuitous, as so far (September 1982) there has been no case of blindness caused by RLF in any of the VLBW infants born and treated at this hospital since the beginning of the study in 1977. A similar prevalence of RLF to ours was reported recently ${ }^{4}$ in a control trial of vitamin $E$ for prevention of RLF, in which a total of 8 cases $(8 \%)$ of cicatricial RLF occurred in 99 control and treated children.

When considering only babies weighing less than $1000 \mathrm{~g}$ at birth, in our series $19 \%$ had cicatricial RLF. This is slightly higher than the figure of $16 \%$ reported by Pape et al..$^{5}$ for babies born in 1974, but 2 of their babies $(5 \%)$ were blind. So the prevalence of cicatricial RLF following the introduction of intensive care units does not seem to have increased significantly, and there seems to have been a decrease in the severity of the disease.

Myopia has been recognised as a common ocular feature in premature infants, ${ }^{6}$ but it has long been suspected that it is mainly associated with RLF. Zacharias et al. ${ }^{7}$ reported that RLF of all degrees would produce myopia, and Kalina ${ }^{8}$ found that myopia was not prevalent when RLF was excluded. Gunn et al. ${ }^{3}$ found myopia in $37 \%$ of cases with RLF and $2 \%$ of cases without RLF. Scharf et al. ${ }^{9}$ did not find any difference in the prevalence of myopia in a group of children weighing between 1000 and $2000 \mathrm{~g}$. and those weighing between 2000 and $2500 \mathrm{~g}$ at birth. but he found an incidence of approximately $43 \%$ of myopia in both, which does not accord with other reports. Shapiro et al. ${ }^{10}$ compared the refractive status in babies weighing between 1750 and $2000 \mathrm{~g}$ with those weighing less than $2000 \mathrm{~g}$ at birth, and found that there was no increase in myopia, but the mean weight of his premature babies was over $1600 \mathrm{~g}$, so any tendency for myopia in the smaller ones may not have been apparent. Kushner ${ }^{11}$ reported no significant difference in the refractive errors found in VLBW infants who were free from RLF changes at 36 weeks gestational and chronological age, and those found in full-term infants when examined at 2 years of age.

The results in our series tend to support the association between RLF and myopia, as 7 of the 8 myopic children had been screened in the premature nursery, and in 6 of them developing RLF had been noted, one was thought to be normal, but later became myopic (R-3.0 DS, L-5.0 DS), and it is not impossible that minor changes were missed in this infant. The difficulties in detection and interpretation of fundus appearances is highlighted by the considerable discrepancy in reports of the prevalence of developing RLF among premature babies.

Hittner et al. ${ }^{12}$ found that $65 \%$ of babies weighing less than $1500 \mathrm{~g}$ showed the changes of developing RLF, while Finer et al. ${ }^{4}$ found a prevalence of $28 \%$ in those weighing under $1000 \mathrm{~g}$ and $20 \%$ of those weighing between 1000 and $1500 \mathrm{~g}$. Keith et al. ${ }^{2}$ found that $23.3 \%$ of those weighing less than $1000 \mathrm{~g}$ and $6 \%$ of those between 1000 and $1500 \mathrm{~g}$ showed RLF changes. The staging classifications for developing -RLF differed slightly in the 3 papers, but this was mainly in the grading rather than in changes observed, so the results should be comparable. However, it seems that the majority of cases of myopia can be predicted from examination in the premature nursery, and only the odd case will be unexpected.

Squint is common among VLBW infants, being found in $21(19 \%)$ out of the 111 children reviewed, and it was also reported (by other ophthalmologists) to be present in 4 of the 66 children not seen by us. On the assumption that there were no other cases of squint, the gross prevalence in the whole cohort is 25 out of $177(14 \%)$. If the 21 cases of cerebral palsy are excluded ( 15 reviewed and 6 not reviewed) because of the high prevalence of squint, and if the 11 cases of RLF are also excluded ( 2 with squint) because of the known existence of ocular abnormalities, we are left with $16(11 \%)$ cases of squint in $145 \mathrm{VLBW}$ infants This is comparable with Kushner's ${ }^{11}$ figure of $13 \%$ for squint among premature babies without RLF or cerebral palsy, while in the group of comparable fullterm infants squint was present in only $2.7 \%$.

Children who developed cerebral palsy were found to have a high ocular morbidity, particularly optic atrophy and squint. Three children in this group had severe optic atrophy causing blindness, and these were the only blind children in the series.

At the Royal Women's Hospital, Melbourne, a significant increase in survival has been achieved, together with a downward trend in the prevalence of strabismus and blindness. This has been reported ${ }^{13}$ in a recent study of 3 cohorts of VLBW infants born in the hospital. For those managed at the time when intensive care was in its early stage of development (1966-70) the long-term survival rate was $37 \%$; $21.6 \%$ had squint, and $3.9 \%$ were blind. For the cohort treated in 1973-4, when intensive care was rather more sophisticated, the long-term survival rate changed little $(37.3 \%)$, but the incidence of squint was reduced to $13.4 \%$, and $3 \%$ of children were blind. In the most recent era (1977-8) 68.5\% of the cohort survived to the age of 2 years, $12.4 \%$ had strabismus, and $1.2 \%$ were blind. Blindness was due to RLF in $1.3 \%$ of children in the first cohort, $1.5 \%$ in the second cohort, and in none of the children in the third cohort. It should be stressed that these results relate only to infants born in the hospital, and so the figures are not strictly comparable with those of the present study. 
The purpose of this survey was to assess the degree of ocular morbidity in VLBW infants, but it was also relevant to assess the value of the screening in the premature nursery for RLF and at 2 years for the detection of ocular morbidity. From the results it seems that if a premature baby does not have cerebral palsy, and is free from RLF changes, then one can expect normal vision, but squint or astigmatism will occur in approximately $18 \%$. For this reason it seems reasonable to continue examinations at 2 years of age, but if RLF, particularly stage III, has been seen, then the child should be more closely monitored after discharge from hospital.

We are grateful to the paediatricians at the Royal Women's Hospital, Dr F. R. Betheras, Dr L. Markman, Dr K. Mountain, Dr L. Murton, and Dr P. Wearne, for allowing us access to their patients; to Miss Kate Hobson for technical assistance, and Mrs Gayle Poor for secretarial assistance.

\section{References}

1 Kitchen WH. Yu VFH, Orgill A, et al. Collaborative study of very-low-birthweight infants, outcome of two-year-old survivors. Lancet 1982; i: $1457-60$.

2 Keith CG. Smith ST, Lansdell JB. Retrolental fibroplasia. A study of the incidence and aetiological factors. Med $J$ Aust 1981; 2: 589-92.

3 Gunn TR. Easdown J, Outerbridge EW, Aranda JV. Risk factors in retrolental fibroplasia. Pediatrics 1980; 65: 1096-100.

4 Finer NN. Schindler RF, Grant G. Hill GB, Peters KL. Effect of intramuscular vitamin $\mathrm{E}$ on frequency and severity of retrolental fibroplasia, a controlled trial. Lancet 1982; i: 1087-91.

5 Pape KE. Buncic RJ. Ashby S. Fitzhardinge PM. The status at two years of low-birth-weight infants born in 1974 with birth weights less than $1001 \mathrm{~g}$. J Pediatr 1978, 92: 253-60.

6 Fletcher MC. Brandon S. Myopia of prematurity. Am J Ophthalmol 1955; 40: 474-81.

7 Zacharias L. Chisholm JF. Chapman RB. Visual and ocular damage in retrolental fibroplasia. Am J Ophthalmol 1962; 53: 337-45.

8 Kalina R. Ophthalmic examination of children of low birth weight. Am J Ophthalmol 1969; 67: 134-6.

9 Scharf J. Zonis S. Zeltzer M. Refraction in premature babies. Metabol Ophthalmol 1978; 2: 395-6.

10 Shapiro A. Yanko L. Nawratzki I, et al. Refractive power of premature infant at infancy and early childhood. Am J Ophthalmol 1980; 90: 234-8.

11 Kushner, BJ. Strabismus and amblyopia associated with regressed retinopathy of prematurity. Arch Ophthalmol 1982; 100: 256-61.

12 Hittner HM. Godio LB. Rudolph AJ, et al. Retrolental fibroplasia; efficacy of vitamin $E$ in a double-blind clinical study of preterm infants. N Engl J Med 1981; 305: 1365-71.

13 Kitchen WH, Ryan MM. Richards A. et al. Changing outcome over 13 years of very low birthweight infants. Semin Perinatol 1982; 6: 373-89. 